\title{
Decontamination Device of Escherichia Coli present in Water using Pulsed Electric Field
}

\author{
Rhemo E. Bacerra ${ }^{1}$, Paulo C. Dela Peña ${ }^{2}$, Iyra Faye T. Jacob ${ }^{3+}$, Earlene A. Sarmiento ${ }^{4}$, Ramon G. \\ Garcia $^{5}$, and Charmaine C. Paglinawan ${ }^{6}$ \\ School of Electrical, Electronics, and Computer Engineering, Mapua University, Philippines

\begin{abstract}
This paper is about the decontamination device for Escherichia Coli present in water using Pulsed Electric Field (PEF). A device that uses lower applied pulse voltage and a specialized treatment chamber that is smaller in scale and more convenient to use compared to conventional PEF systems. Log reduction method was used to determine how much bacteria were decontaminated after the PEF treatment. There were seven tests with an initial E. Coli count of 120,000 CFU/ml that resulted to no bacteria growth, ad at a pulse voltage of $110 \mathrm{~V}$, and frequency of $500 \mathrm{~Hz}$ regardless if the used duty cycle is $10 \%, 30 \%$, or $50 \%$ in the procedure, it produced total reduction of E. coli bacteria. The treated water that underwent PEF process passed the potability test which used Heterotrophic Plate Count (HPC) that resulted to below the standard value of less than $500 \mathrm{CFU} / \mathrm{ml}$, therefore the PEF-treated water is potable.
\end{abstract}

Keywords: decontamination device, Escherichia coli, pulsed electric field

\section{Introduction}

Existing devices are present in the industry, these devices are large scale in terms of its appearance and uses very high voltage making it very dangerous and expensive to operate. Unlike those of the previous studies, this study used lower applied pulse voltage compared to conventional PEF systems without greatly affecting the electric field intensity due to the electrode design pattern used. Also, a specialized treatment chamber that is smaller in scale and convenient to use compared to existing chambers was fabricated for the PEF process.

The main objective of this study is to create a water decontaminating device which uses pulsed electric field as means of killing bacteria, especially for E. coli. The main objective of this study can be attained through these sub-objectives: (a) to modify the design of electrodes in treatment chamber, and (b) to analyze the parametric effects contributing to the pulsed electric field performance. (c) Lastly, to determine the potability of the water after implementing the pulsed electric field system.

\subsection{Pulsed Electric Field}

The very first use of pulsed electric field (PEF) was proposed by Doevenspeck in the early 1960s to inactivate microorganisms for faster fermentation. In 1967, Hamilton and Sale attested that the microbial inactivation when undergoing PEF process was due to effect of PEF treatment and not on electrolysis or temperature increase. Nowadays, PEF is regarded as one of the most promising non-thermal methods for inactivating microorganisms. PEF is commonly used on the production of foods and beverages due to the PEF not affecting the quality of these products [1]. The PEF related equipment for technical requirements are constantly improving but not all can satisfy the requirements especially production of high voltage electric field due to large cost and the concern for safety of the operator [2]. The main current drifts

\footnotetext{
+ Corresponding author.

E-mail address: iftjacob@mymail.mapua.edu.ph
} 
through the outside part of the cell at low frequency pulses. While at high frequency pulses, the electric field became more uniform and the current directly penetrates the cell membrane [3].

\subsection{PEF System}

PEF is commonly used on the production of foods and beverages due to the PEF not affecting the quality of these products [4]. The PEF technology is based on the electric field produced by the pulse generator and its intensity applied on the set of electrodes confined in the treatment chamber. Application of pulsed electric field will introduce membrane electroporation that causes temporary or permanent permeabilization, then swelling and eventually the rupture of the cell membrane [5]. It moves the ions to the internal and external surfaces of the cell membrane of the bacteria which causes stress to the cell membrane which then forms pores. [6]. When these micro-pores do not close it would cause irreversible electroporation then cells would die. The treatment chamber is where electroporation of microorganisms happens. The effectiveness of the process relies on the design of the treatment chamber. The PEF system is mainly composed of the pulse generator, the treatment chamber, and the flow system intended for the process [7].

\subsection{Inactivation of E. Coli}

Escherichia coli or E. coli is type of bacteria which causes nausea, vomiting, fever, and bloody diarrhea. Although it is a natural component of the human body and not a health threat itself, it is used as an indicator of whether pathogenic disease-causing organisms are present in water which poses a great threat to human health when ingested [8]. An increase in the inactivation is reported with the increase of pulse frequency or the number of pulses applied per sample in a certain amount of time [9]. The pulse width or the exposure of the bacteria to the pulse is also considered under treatment time. Consider, if a set-up has a pulse duration of one second and the bacteria is given two pulses it will just be equivalent to a pulse duration of two seconds with the bacteria exposed on a single pulse. PEF would effectively inactivate the E coli growth. As pulse number increased, the effect of PEF may inversely decline [10]. The study provided a definite number of pulse to effectively inactive E. coli. E. coli is easier to be sterilized at lower temperature; this means solely depending on PEF is better than using heating process.

\section{Methodology}

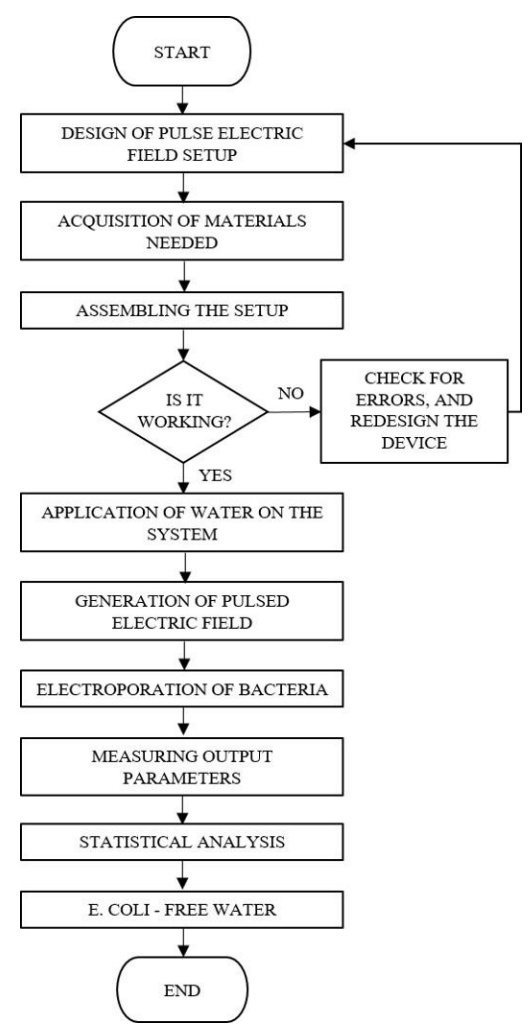

Fig. 1: PEF system. 
The researchers built a decontamination device for Escherichia Coli present in water using pulsed electric field. First step, the researches designed the setup for the pulsed electric field procedure. Cultured water samples were used as test subjects for the procedure. Then, the designed setup was tested for its precise functionality and possible errors within the process for creation of the final device were determined. When the device was ready, the application of water in the system was made, followed by the generation of the pulsed electric field to the electrodes and electroporation of E. coli bacteria occurred. After that, the researchers measured the output parameters, gathered the test results, and then applied statistical analysis. Then, the expected E. coli-free was obtained.

\subsection{Actual Setup}

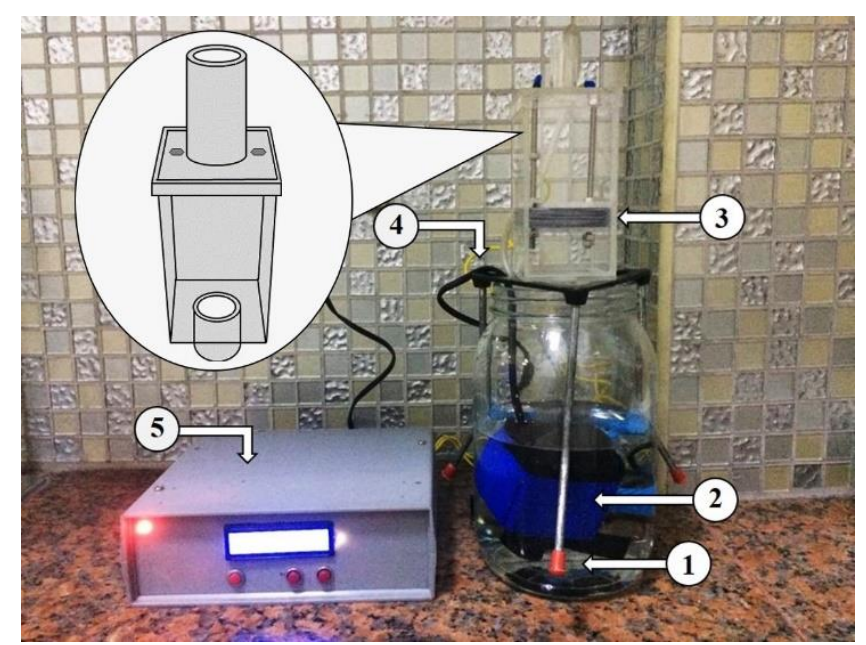

Fig. 2: Actual setup of PEF system.

The actual setup is consisted of the (1) water samples (controlled water) with Escherichia Coli, (2) water pump motor, (3) PEF treatment chamber which was supported by a (4) Bunsen burner tripod, and a (5) pulse generator.

\subsection{Application of Water on the System}

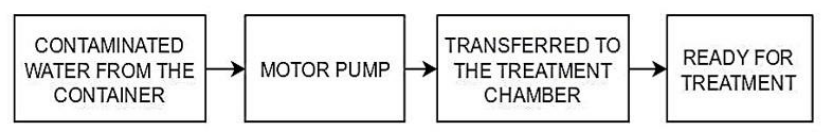

Fig. 3: Block diagram for application of water on the system.

Figure 3 illustrates the application of water on the PEF system. The contaminated water was pumped out continuously by a motor pump to the treatment chamber at a flow rate of $350 \mathrm{ml}$ per minute. The decontamination of the $500 \mathrm{ml}$ contaminated water sample occurs inside the treatment chamber.

\subsection{Generation of Pulsed Electric Field}

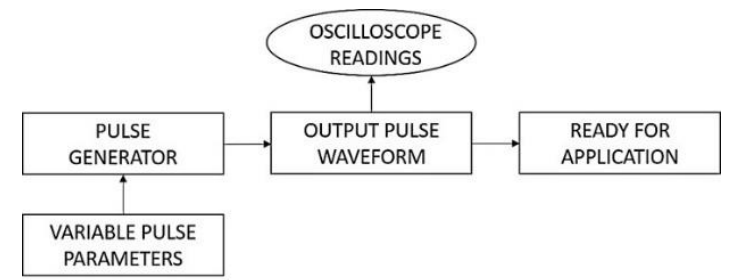

Fig. 4: Block diagram for the generation of pulsed electric field.

Figure 4 shows the generation of pulsed electric field. The pulse generator produces pulses of electricity which are used to electroporate bacteria. It has variable pulse parameters like pulse voltage, pulse frequency, 
and pulse duty cycle. The pulsed electric field can be produced by applying voltage in the electrodes. The output waveform and other parameters were checked using an oscilloscope. The pulse generator used in the study is powered by an Arduino UNO to process the sequence of operation needed to attain the desired output values of voltage, frequency and duty cycle.

\subsection{Electroporation of E. Coli bacteria}

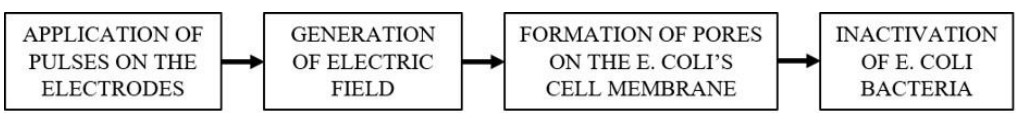

Fig. 5: E. Coli electroporation process.

In Figure 5, the block diagram for the electroporation of E. coli bacteria is shown. The voltage pulses were applied to the electrodes which created an electric field that was used for the bacteria inactivation. This generated electric field caused electroporation of the bacteria's cell membrane. Therefore, an irreversible electroporation uses electric field to inactivate bacteria.

\section{Results}

Laboratory tests were done to observe the effects of the three pulse parameters leading to E. Coli bacteria decontamination. A total of 48 tests or combinations of the three parameters were done to analyze the parametric effects. The initial and final microbial count together with the calculated log reduction value for each test procedure were tabulated on table I.

Table 1: Pulse parameters, untreated and treated e. coli count, and equivalent log

\begin{tabular}{|c|c|c|c|c|c|}
\hline \multicolumn{6}{|c|}{$\begin{array}{l}\text { Volume: } 500 \mathrm{~mL} \\
\text { Treatment Time }=5 \mathrm{mins}\end{array}$} \\
\hline $\begin{array}{c}\text { Pulse } \\
\text { Voltage } \\
\text { (V) }\end{array}$ & $\begin{array}{c}\text { Pulse Frequency } \\
\text { (Hertz) }\end{array}$ & $\begin{array}{l}\text { Duty } \\
\text { Cycle }\end{array}$ & $\begin{array}{c}\text { E. coli Count } \\
\text { (cfu/mL) } \\
{ }^{*} \text { BEFORE* }\end{array}$ & $\begin{array}{c}\text { E. coli Count } \\
\text { (cfu/mL) } \\
\text { *AFTER* }\end{array}$ & $\begin{array}{l}\text { Log Reduction } \\
(\log \text { cfu/mL) }\end{array}$ \\
\hline \multirow{4}{*}{30} & \multirow{2}{*}{50} & $10 \%$ & 100,000 & 80,000 & 0.10 \\
\hline & & $50 \%$ & 100,000 & 75,000 & 0.12 \\
\hline & \multirow{2}{*}{500} & $10 \%$ & 100,000 & 70,000 & 0.15 \\
\hline & & $50 \%$ & 100,000 & 65,000 & 0.19 \\
\hline \multirow{4}{*}{70} & \multirow{2}{*}{50} & $10 \%$ & 120,000 & 50,000 & 0.38 \\
\hline & & $50 \%$ & 120,000 & 45,000 & 0.43 \\
\hline & \multirow{2}{*}{500} & $10 \%$ & 120,000 & 16,000 & 0.88 \\
\hline & & $50 \%$ & 120,000 & 11,000 & 1.04 \\
\hline \multirow{9}{*}{90} & \multirow{3}{*}{50} & $10 \%$ & 120,000 & 45,000 & 0.43 \\
\hline & & $30 \%$ & 120,000 & 40,000 & 0.48 \\
\hline & & $50 \%$ & 120,000 & 30,000 & 0.60 \\
\hline & \multirow{3}{*}{250} & $10 \%$ & 120,000 & 9,000 & 1.12 \\
\hline & & $30 \%$ & 120,000 & 5,000 & 1.38 \\
\hline & & $50 \%$ & 120,000 & 3,000 & 1.60 \\
\hline & \multirow{3}{*}{500} & $10 \%$ & 120,000 & 2,000 & 1.78 \\
\hline & & $30 \%$ & 120,000 & 0 & TOTAL REDUCTION \\
\hline & & $50 \%$ & 120,000 & 0 & TOTAL REDUCTION \\
\hline \multirow{12}{*}{110} & \multirow{3}{*}{50} & $10 \%$ & 120,000 & 35,000 & 0.54 \\
\hline & & $30 \%$ & 120,000 & 28,000 & 0.63 \\
\hline & & $50 \%$ & 120,000 & 23,000 & 0.72 \\
\hline & \multirow{3}{*}{100} & $10 \%$ & 120,000 & 12,000 & 1.00 \\
\hline & & $30 \%$ & 120,000 & 10,000 & 1.08 \\
\hline & & $50 \%$ & 120,000 & 5,000 & 1.38 \\
\hline & \multirow{3}{*}{250} & $10 \%$ & 120,000 & 2,000 & 1.78 \\
\hline & & $30 \%$ & 120,000 & 0 & TOTAL REDUCTION \\
\hline & & $50 \%$ & 120,000 & 0 & TOTAL REDUCTION \\
\hline & \multirow{3}{*}{500} & $10 \%$ & 120,000 & 0 & TOTAL REDUCTION \\
\hline & & $30 \%$ & 120,000 & 0 & TOTAL REDUCTION \\
\hline & & $50 \%$ & 120,000 & 0 & TOTAL REDUCTION \\
\hline
\end{tabular}

The initial E. Coli count for the $30 \mathrm{~V}$ and $50 \mathrm{~V}$ tests was $100,000 \mathrm{cfu} / \mathrm{ml}$ while for the $70 \mathrm{~V}, 90 \mathrm{~V}$, and $110 \mathrm{~V}$ tests, the initial E. Coli count was $120,000 \mathrm{cfu} / \mathrm{ml}$. From the results table, at a pulse voltage of $30 \mathrm{~V}$ there were not much of a reduction of bacteria and a slight increase at pulse voltage equal to $50 \mathrm{~V}$. Better decontamination was achieved at $70 \mathrm{~V}, 500 \mathrm{~Hz}$, and $50 \%$ duty cycle which is equal to $90.83 \%$ reduction or $1.04 \log$ reduction. For the $90 \mathrm{~V}$ and $110 \mathrm{~V}$ tests, the $30 \%$ duty cycle row was added to better analyze the effects of duty cycle. At $90 \mathrm{~V}$ pulse voltage, two total reduction or complete decontamination of E. Coli tests occurred. For the last series of test at pulse voltage equal to $110 \mathrm{~V}$, the five last tests yielded to total decontamination. 


\subsection{Potability Test}

The test result that yielded to total reduction or total decontamination was used to undergo water quality analysis to determine if other water parameters were affected aside from the decontamination of E. Coli. The water that underwent PEF treatment with pulse parameters of $110 \mathrm{~V}, 500 \mathrm{~Hz}$, and $50 \%$ duty cycle was used for the potability test. The standards set by Philippine National Standards for Drinking Water (PNSDW) is that the sample to be tested should have a value less than 500 Colony Forming Units/ml for the HPC. Table II shows the results for the potability test of the untreated and treated water samples.

Table 2: Potability test results

\begin{tabular}{|c|c|c|c|}
\hline ANALYSIS & METHOD & $\begin{array}{c}\text { UNTREATED WATER } \\
\text { (BEFORE) }\end{array}$ & $\begin{array}{c}\text { TREATED WATER } \\
\text { (AFTER) }\end{array}$ \\
\hline $\begin{array}{c}\text { Heterotrophic Plate } \\
\text { Count (CFU/ml) }\end{array}$ & $\begin{array}{c}\text { Pour Plate } \\
\text { Method }\end{array}$ & $>5700 \mathrm{CFU} / \mathrm{ml}$ & $120 \mathrm{CFU} / \mathrm{ml}$ \\
\hline \multicolumn{2}{|r|}{ REMARKS } & FAILED & PASSED \\
\hline
\end{tabular}

Based on the results on the table II, it can be observed that the untreated water failed the test done as the result was way above the standards given by the PNSDW. On the other hand, the treated water had 120 $\mathrm{CFU} / \mathrm{ml}$ result on its HPC which is below the standard, therefore it passed. Based on the HPC result, there were still bacteria present in the water after undergoing PEF treatment but no signs of E. Coli bacteria were found on the sample. Since, the treated sample was under the standard of the HPC, it can be said that the treated water passed the test and it is potable.

\section{Conclusion}

The log reduction is directly proportional to the three pulse parameters. There were seven tests with an initial E. Coli count of 120,000 CFU/ml that resulted to no bacteria growth, and at a pulse voltage of $110 \mathrm{~V}$ and $500 \mathrm{~Hz}$ regardless if the used duty cycle is $10 \%, 30 \%$, or $50 \%$ in the procedure, it produced total reduction of E. coli bacteria. The water that underwent PEF treatment with pulse parameters of $110 \mathrm{~V}$ with an equivalent electric field intensity of $4.933 \mathrm{kV} / \mathrm{cm}, 500 \mathrm{~Hz}$, and $50 \%$ duty cycle was used for the potability test. The Heterotrophic Plate Count of the treated water was below the standard value of less than $500 \mathrm{CFU} / \mathrm{ml}$; therefore, the PEF-treated water is potable.

\section{Acknowledgement}

To the School of Electrical, Electronics and Computer Engineering (EECE), thank you for the opportunity which engaged us in activities encompassing wide areas of our program, Electronics Engineering. Special thanks to Dean Alejandro H. Ballado Jr., Engr. Marloun Sejera, the ECE Chairperson and our panel member; Engr. Joseph Bryan G. Ibarra and Engr. Mary Ann F. Latina as members of our panel. To our thesis advisers, Engr. Ramon G. Garcia and Engr. Charmaine C. Paglinawan. To Mary Mediatrix Medical Center, for their authorized laboratory personnel and testing facilities.

\section{References}

[1] Kinetics of Microbial Inactivation for Alternative Food Processing Technologies. (2000). JOURNAL OF FOOD SCIENCE, 65(8), pp. 65-70.

[2] Yang Z., Jiang Y., and Xiong L., "Study on Pulsed electric field application to water treatment system," 2008 World Automation Congress, Hawaii, HI, 2008, pp. 1-5

[3] C. B. Arena, M. B. Sano, M. N. Rylander and R. V. Davalos, "Theoretical Considerations of Tissue Electroporation with High-Frequency Bipolar Pulses," in IEEE Transactions on Biomedical Engineering, 58(5), pp. 1474-1482, May 2011.

[4] Kinetics of Microbial Inactivation for Alternative Food Processing Technologies. (2000). JOURNAL OF FOOD SCIENCE, 65(8), pp. 65-70.

[5] Saulis, G. (2010). Electroporation of Cell Membranes: The Fundamental Effects of Pulsed Electric Fields in Food Processing. Food Eng. Rev. Food Engineering Reviews, 2(2), 52-73.

[6] Y. Murakami, Y. Muramoto and N. Shimizu, Influence of ion concentration in aqueous solution on sterilization of 
E. coli by high electric field pulse. 2014 IEEE Conference on Electrical Insulation and Dielectric Phenomena (CEIDP), 2014

[7] Amer Eissa, A.H, and E.A Mohamed (2012). Pulsed Electric Fields for Food Processing Technology, Structure and Function of Food Engineering, InTech, 276-306.

[8] Blas II, E., Candaroma, M. and Biag, K. (2015). The Effectiveness of CE581 Water Treatment Plant 1 installed at the Mapua Institute of Technology for the Removal of Various Chemicals and E. Coli in Water Supply. Manila, p.22.

[9] Lodes, A., Curry, R. D., Narsetti, R., \& Nichols, L. M. (2006). Pulsed Electric Fields Inactivation of Vegetative Bacteria in Drinking Water Utilizing Magnetic Pulse Compressor Technology. Conference Record of the 2006 Twenty-Seventh International Power Modulator Symposium.

[10] H. Liu, W. Xie, J. Yuan, H. Li, P. Jiang, L. Wang, T. Jiang and Q. Zhang, Fast pulsed generator based on PCSS for killing pathogen in blood. 2014 IEEE International Power Modulator and High Voltage Conference (IPMHVC), 2014. 